\title{
A TEORIA DA DESCONSIDERAÇÃO DA PERSONALIDADE JURÍDICA NO CÓDIGO CIVIL DE 2002
}

\author{
Maxwel Gomes dos Santos ${ }^{1}$
}

RESUMO: Este trabalho aborda a teoria da desconsideração da personalidade jurídica no Novo Código Civil de 2002. Sem esgotar a matéria, analisam-se os conceitos de pessoa jurídica, a teoria da desconsideração da personalidade jurídica e seu desenvolvimento, bem como o tratamento legislativo dado à matéria pelo Código Civil Brasileiro.

PALAVRAS-CHAVE: personalidade jurídica - disregard doctrine.

\section{A theory of the diregard of legal entity of the Brazilian Civil Code 2002}

ABSTRACT: This paper discusses the theory of disregard doctrine in the New Civil Code of 2002. Without exhausting the subject are analyzed in terms of the legal person, the theory of the disregard of legal entity and its development as well as the treatment given to the legislative by Brazilian Civil Code.

KEY-WORDS: legal entity, disregard doctrine.

\section{INTRODUÇÃO}

O presente trabalho tem como tema a teoria da desconsideração da personalidade jurídica no Novo Código Civil de 2002. Uma motivação de ordem teórica para o estudo apresentado reside na possibilidade de responder ao questionamento se a aplicação da disregard doctrine representa um rompimento com o entendimento segundo o qual a pessoa jurídica e seus membros têm existência distinta, bem como especular sobre os possíveis limites para aplicação da doutrina da desconsideração.

Adverte-se que este artigo não tem a pretensão de esgotar o tema abordado e nem tampouco se acredita que seja suficiente para dissipar as controvérsias inerentes às diversas abordagens que a teoria sob enfoque permite.

Analisam-se os conceitos de pessoa jurídica, a teoria da desconsideração da personalidade jurídica e seu desenvolvimento, bem como o tratamento legislativo dado à matéria pelo Código Civil Brasileiro.

\footnotetext{
1 Bacharel em Direito(2001); especialista em Gestão Agroindustrial (2004) e Direito Eleitoral e Processual Eleitoral (2007); Analista Judiciário - Área Judiciária do Tribunal Regional Eleitoral de Minas Gerais, professor Universitário de Direito Comercial e de Direito Tributário na Universidade Estadual de Montes Claros (MG). E-mail <maxweladv@ig.com.br>
} 


\section{CONCEITO E NATUREZA DA PESSOA JURÍDICA E SUA RELAÇÃO COM A DISREGARD DOCTRINE}

A simples observação da realidade fática permite constatar que muitas vezes um indivíduo sozinho não é capaz de realizar certos empreendimentos que suplantam suas forças ou sua capacidade de investimentos. Daí, ele se ajunta a outros indivíduos, a fim de suplantar essa limitação. Diz-se, pois, que o homem é um animal social e tal acertiva já fora aventada pelos antigos filósofos gregos. Nesse sentido, dizia Aristóteles (1998, p. 1-6) que todas as sociedades tem como meta alguma vantagem e o homem é um animal cívico, mais social do que as abelhas e os outros animais que vivem juntos. Ele não prescinde de formar sociedade, pois, aquele que não precisa dos outros homens, ou não pode resolver-se a ficar com eles, ou é um bruto, ou é um deus.

Para Washinton de Barros Monteiro (1996, p. 97), o homem, para atingir certos fins une-se a outros homens de modo que sua atividade acrescentada à dos demais não se soma, mas se multiplica quase ao infinito, ampliando suas possibilidades e propiciando a execução de obras extraordinárias e duráveis em benefício da comunidade. Por isso, conclui ele, "objetivos inatingíveis para um só homem são facilmente alcançados pela reunião dos esforços combinados de várias pessoas".

De fato, do ponto de vista do Direito Empresarial, a consideração de que o fenômeno associativo produz resultados que muitas vezes não se poderia alcançar sozinho pode ser constatado pelo grande número de sociedades empresárias que requerem grande mobilização de capital para tocar o negócio. Assim, o ordenamento jurídico reconhece a capacidade das sociedades gerarem riquezas e estimula a atividade produtiva pelo maior número de pessoas, através de institutos jurídicos que limitam a responsabilidade dos sócios.

O reconhecimento de personalidade jurídica a determinados entes coletivos são, conforme Marçal Justein Filho (1979), uma sanção positiva assegurada pelo direito a quem adotar a conduta desejada. Isto é, a favorabilidade do regime (o regime da pessoa jurídica) reside, fundamentalmente, em afastar as regras jurídicas que seriam aplicáveis ao indivíduo que, isoladamente, exercesse determinada atividade.

As pessoas jurídicas, portanto, coexistem ao lado de indivíduos humanos. De acordo com Silvio Rodrigues (1985, p. 66), "são entidades a que a lei empresta personalidade, isto é, são seres que atuam na vida jurídica, com personalidade diversa 
da dos indivíduos que os compõem, capazes de serem sujeitos de direitos e obrigações na ordem civil".

$\mathrm{Na}$ doutrina, várias são as teorias que buscam explicar a natureza da pessoa jurídica. Embora o presente trabalho se exima de tecer maiores considerações acerca de tais teorias, vez que exorbita o objeto proposto, cumpre informar quais são as mais difundidas. Isso, porque, conforme a teoria adotada, muda-se o enfoque quanto às razões que levam o ordenamento jurídico a atribuir personalidade jurídica a determinadas formas de organizações sociais.

Segundo Luiz Ferreira Xavier Borges (2001), há os adeptos da teoria da ficção, destacando-se dentre seus defensores Saviny; teoria da equiparação, sustentada por Windcheid; a teoria da realidade objetiva, bem como a teoria institucional.

A teoria da ficção constitui a doutrina tradicional e parte do princípio de que somente o homem é capaz de ser sujeito de direitos. Nessa concepção, a pessoa jurídica seria uma criação artificial da lei para o exercício de direitos patrimoniais. Tal personalidade seria obtida através de abstrações.

A teoria da equiparação nega qualquer personalidade jurídica como substância As pessoas jurídicas seriam meros patrimônios personificados pelo direito, tendo me vista o objetivo a ser conseguido. Admite que determinados patrimônios, no seu tratamento, equiparem-se às pessoas naturais.

Para a teoria da realidade objetiva, também chamada de teoria orgânica, junto às pessoas naturais, há organismos sociais que tem vida autônoma e vontade própria, cuja finalidade é a realização do fim social. Tais corpos sociais ou pessoas jurídicas, o direito não cria, mas se limita a declarar existentes.

Segundo a teoria institucionalista, a instituição preexiste ao momento do nascimento da pessoa jurídica. A idéia de sua constituição envolve a idéia de vínculo social e organização com vistas à consecução de um fim comum. Quando a instituição alcança certo grau de concentração e de organização é que se torna uma pessoa jurídica.

Suzy Elizabeth Cavalcante Koury (2000, p. 1-3) reúne as principais teorias em dois grupos, um que considera tais entes como reais aos quais o ordenamento jurídico empresta personalidade, e outro que afirma serem elas criações do ordenamento jurídico, instrumentos para consecução de objetivos práticos. Conforme a mesma autora, seria evidente que os diversos entendimentos acerca da natureza da personalidade jurídica assumissem distinções básicas e fundamentais, mas não de modo a invalidar essa classificação bipartite: a teoria da ficção e a da realidade objetiva. 
A técnica da personificação, explica Koury (2000, p. 12-130), além de atender à unificação das relações próprias de uma coletividade, atende também ao objetivo de limitação e, até mesmo, supressão de responsabilidades individuais. Visa a estimular a atividade produtiva e a concentração de esforços, através do maior ingresso de pessoas em empreendimentos que produzam satisfação para os membros do corpo social e que gerem riquezas para a comunidade como um todo.

O Código Civil de 1916 trazia expressamente no seu artigo $20^{2}$ que as "pessoas jurídicas têm existência distinta da dos seus membros". Conforme Clóvis Bevilaqua (1951):

A conseqüência imediata da personificação da sociedade é distingui-la, para os feitos jurídicos, dos membros, que a compõem. Pois que cada um dos sócios é uma individualidade e a sociedade uma outra, não há como lhes confundir a existência. A sociedade, constituída por seu contracto, e personificada pelo registro, tem um fim próprio, econômico ou ideal; move-se, no mundo jurídico, a fim de realizar esse fim; tem direitos seus, e, em regra, um patrimônio, que administra, e com o qual assegura, aos credores, a solução das dívidas, que contráe. (sic)

Sem repetir o artigo 20 do revogado Código, o Novo Código Civil de 2002 não deixa dúvida de que o ente criado de acordo com as prescrições legais goza de inteira autonomia em relação às pessoas físicas que dele fazem parte, possuindo, inclusive, patrimônio distinto. Neste sentido, dispõe no art. 45 que "começa a existência legal das pessoa jurídicas de direito privado com a inscrição do ato constitutivo no respectivo registro" e, mais, no art. 47 diz que "Obrigam a pessoa jurídica os atos dos administradores, exercidos nos limites de seus poderes definidos no ato constitutivo". O artigo 52 manda aplicar às pessoas jurídicas, no que couber, a proteção dos direitos da personalidade e o artigo 53 reza que "Não há, entre os associados, direitos e obrigações recíprocos".

Contudo, a técnica da personificação tem sofrido críticas, na medida em que possibilita o seu uso para atingir resultados reprováveis. Conforme Borges (2000, p. 330), alguns sócios "passaram a valer-se, de forma sistemática, da autonomia patrimonial da sociedade comercial para fugir ao adimplemento de obrigações, valendose dos princípios que nortearam a separação para burlar a lei e prejudicar terceiros”.

\footnotetext{
${ }^{2}$ Sem correspondente no Código Civil de 2002.
} 
Em razão dos abusos no uso da personalidade jurídica, ganhou força no Brasil a teoria da desconsideração da personalidade jurídica, também conhecida como disregard doctrine, teoria da penetração, disregard of legal entity, que permite, em algumas situações, levantar o véu da personificação- jurídica e alcançar o patrimônio pessoal dos sócios ou administradores.

Não se trata de extinguir a personalidade jurídica, mas de deixar de reconhecer seus efeitos em dadas situações.

Koury (2000, p. 2) destaca que nenhuma das teorias acerca da existência da personalidade jurídica afasta a aplicação da disregard doctrine, como nenhuma delas pode ser tida como a mais adequada para justificá-la. O essencial é que se opere a disregard doctrine é a existência da personalidade jurídica. Borges $(2000,335)$ afirma, contudo, que conforme seja a teoria adotada, diverso será o enfoque dado à desconsideração: “Quem sustenta a concepção ficcionista para a pessoa jurídica, como mera criação legal, entende que igualmente a lei pode a qualquer momento suspender seus efeitos. Para os adeptos da teoria realista, a desconsideração seria um instrumento do direito positivo para adequar as construções jurídicas a seus referenciais metajurídicos".

\subsection{Desenvolvimento, conceito e aplicação da disregard doctrine}

Rubens Requião (1982, p. 267-8) informa que a origem da doutrina da desconsideração da personalidade jurídica remonta ao precedente inglês "Salomon v. Salomon \& Co.”. O caso aconteceu em Londres, no ano de 1897. Aaron Salomon e mais seis parentes se reuniram e criaram uma company, a "Salomon \& Co.". A cada um dos familiares tocara uma ação, ao passo que Salomon subsrevera 20.000 ações, pagando-as com seu fundo de comércio. Salomon tornou-se credor privilegiado da sociedade por ter-lhe vendido o estabelecimento e recebido obrigações garantidas por hipoteca. Não demorou muito tempo e a sociedade revelou-se insolvente. Porém, sendo pagos os créditos privilegiados, isto é, os créditos do próprio Salomon, nada sobraria aos credores quirografários.

Ainda conforme Requião (1982), que:

O liquidante, no interesse dos credores quirografários, sustentou que a atividade da company era atividade de Salomon, que usou de artifício para limitar a sua responsabilidade e, em consequência, Salomon deveria ser condenado ao pagamento dos débitos da company, devendo asoma investida na liquidação de seu 
crédito privilegiado ser destinado à satisfação dos credores da sociedade. O juízo de primeira instância e depois a Corte acolheram essa pretenso, julgando que a company era exatamente uma entidade fiduciária de Salomon, ou melhor, um seu agent ou trustee, e que ele, na verdade, permanecera como o efetivo proprietário do fundo de comércio. Era a aplicação de um novo entendimento, desconsiderando a personalidade jurídica de que se revestia Salomon \& Co. (REQUIÃO, 1982, p. 268)

Ocorre, porém, que a Casa dos Lordes, reformou aquela decisão, unanimemente, ao argumento de que a company "Salomon \& Co." havia sido constituída validamente, sendo, pois, distintas as personalidades dos sócios das pessoas que compunham a sociedade. Segundo Antônio Carlos Bottan (2001, p. 128), a repercussão do caso desestimulou os juristas britânicos a aprofundarem-se no tema, de modo que a disregard doctrine não teve, na Inglaterra, grande repercussão, tanto no plano teórico, como na jurisprudência.

De acordo com Suzy Elizabeth Cavalcante Coury (2000, p. 64), a doutrina da desconsideração da personalidade jurídica, ao invés da Inglaterra, teria originado-se nos Estados Unidos da América, em 1809, no caso "Bank of United States v. Deveaux", quando o juiz Marshall conheceu do caso, com a intenção de preservar a jurisdição das cortes federais sobre as corporations. As cortes levantaram o véu e consideraram as características dos sócios individuais.

No Brasil, segundo Borges (2001, p.331), coube a Rubens Requião, pioneiramente, abordar a questão da disregard doctrine, em conferência realizada na Faculdade de Direito da Universidade do Paraná, publicada, posteriormente, no ano de 1969, na Revista dos Tribunais 410/12. A partir daí, o tema passou a ser objeto de apreciação de diversos doutrinadores, juízes e tribunais. Mais tarde foi adotada, expressamente, no artigo 28 do Código de Defesa do Consumidor.

Em seus estudos, Requião (1982, p. 331) focaliza que essa doutrina tem o propósito de demonstrar que a "personalidade jurídica não constitui um direito absoluto, mas está sujeita e contida pela teoria da fraude contra credores e pela teoria do abuso de direito".

Koury (2000, p. 141) afirma que a preocupação dos doutrinadores com a fundamentação legal que justificasse o uso do instituto levou-os, sob o regime do revogado Código Civil de 1916, à míngua de previsão expressa para aplicar a disregard doctrine, a recorrer às regras gerais de eficácia dos atos jurídicos, reportando aos elementos dos atos jurídicos, ao regime das nulidades e anulabilidades dos atos jurídicos, bem como à teoria do abuso de direito. Uma vez identificado o fím lícito dos 
sócios da pessoa jurídica, tais princípios gerais então positivados pelo direito civil autorizariam a punição deles, sem, entretanto, desconstituir a pessoa jurídica.

Posteriormente, o Código Civil de 2002, no artigo 50, veio a cuidar do tema nos seguintes termos: "Em caso de abuso da personalidade jurídica, caracterizado pelo desvio de finalidade, ou pela confusão patrimonial, pode o juiz decidir, a requerimento da parte, ou do Ministério Público quando lhe couber intervir no processo, que os efeitos de certas e determinadas relações de obrigações sejam estendidos aos bens particulares dos administradores ou sócios da pessoa jurídica."

Um ponto a ser esclarecido e que fica evidente é o de que a desconsideração da personalidade jurídica não se presta à dissolução da sociedade, mas somente desconsiderar os efeitos da personificação em determinadas situações, no caso concreto apresentado para julgamento, permanecendo, contudo, válidos os efeitos da personificação para todos os demais atos não atingidos.

Também deve-se levar em consideração que a disregard doctrine não pode ser usada de forma indiscriminada, de modo que imponha total comunhão entre o patrimônio do sódio e o da sociedade. Do mesmo modo que é relativa a personificação social, quer em atenção aos referenciais metajurídicos, quer sob a finalidade de se conceder autonomia patrimonial a entes sociais tendo em vista a consecução de seus fins, deverá a disregard doctrine ser empregada de forma compatível com o ordenamento jurídico como um todo. Não se trata, pois, de invalidar o princípio que torna a sociedade ente distinto das pessoas dos sócios.

Conforme Borges (2000), o estudo da teoria da desconsideração:

constitui uma ferramenta nova e importante, que deve ser analisada como um instituto ainda evolução, cuja aplicação mais abrangente, em longe de servir para a proteção dos credores, pode pôr em xeque, através de sentenças isoladas, o próprio instituto da personificação das sociedades, paralisando o crédito pela descoberta de possíveis credores preferenciais ocultos, em função de direitos contra suas controladas coligadas. (BORGES, 2000, p. 332)

A doutrina também critica a possibilidade da desconsideração da personalidade jurídica ser utilizada para punir os atos de má gestão, ou praticados com excessos por parte de sócios e administradores. Segundo Koury (2000):

É preciso notar que, em determinadas circunstâncias, sócios, administradores e gerentes podem responder por dívidas da sociedade. Essa medida tem caráter excepcional e visa a punir aqueles que tenham agido com excesso de poderes ou de 
maneira contrária à lei o aos estatutos. Não há que falar aqui em desconsideração da personalidade jurídica pois esta não foi manipulada, não serviu como "véu" para que tais pessoas agissem e não pudessem ser responsabilizadas. (KOURY, 2000, p. 86)

Em tais situações, seria caso de simples imputação de responsabilidade àquele que praticou o ato, ficando afastada a aplicação da diregard of legal entity em casos que a lei ou atos constitutivos da sociedade determinem a punição a determinadas pessoas por atos de má administração ou excessos de poderes. Somente se utiliza do instrumento da desconsideração se para a prática do ato houve necessidade de ocultamento sobre o manto da pessoa jurídica.

Koury (2000, p. 79) conclui que cabe superar o véu da personalidade jurídica "nos casos em que a aplicação do regime de personificação societária desvie a sociedade da finalidade que o ordenamento jurídico vise a alcançar por seu intermédio; nos caos em que tal aplicação conduza a situações de injusto prejuízo ao Estado ou à coletividade nele organizada; e, ainda, quando sua aplicação produza efeitos contrários aos valores que inspiram o ordenamento jurídico"

\section{CONSIDERAÇÕES FINAIS}

De todo o exposto, pode-se concluir que é difícil formular um conceito único aplicável a todas as hipóteses em que se permite seja aplicada a doutrina da desconsideração da personalidade jurídica.

A despeito disso, o Código Civil de 2002 deu tratamento legislativo à diregard doctrine, consistindo esta na possibilidade de o juiz, face ao caso concreto submetido a julgamento, suspender os efeitos da pessoa jurídica, sem, contudo, anulá-la, para responsabilizar a pessoa que por traz dela se oculta.

A finalidade desse instituto jurídico consiste em impedir que a pessoa jurídica seja desviada dos fins estabelecidos no ato constitutivo, em caso de abuso da personalidade jurídica, caracterizado pelo desvio de finalidade, ou pela confusão patrimonial. 


\section{REFERÊNCIAS BIBLIOGRÁFICAS}

ARISTÓTELES. A política. Título original La Politique, tradução de Roberto Leal Ferreira, 2. ed. São Paulo: Martins Fontes, 1998.

BEVIAQUA, Clóvis. Código civil dos Estados Unidos do Brasil commentado. v. 1., 9. ed. Rio de Janeiro: Paulo Azevedo, 1951.

BORGES, Luiz Ferreira Xavier. A teoria da desconsideração da personalidade jurídica e sua aplicação em análise de crédito. Revista do BNDES, Rio de Janeiro, v. 7., n. 14. Dezembro de 2000.

BOTTAN, Antônio Carlos. A desconsideração da personalidade jurídica - disregard doctrine. Cidadania e justiça - revista da Associação dos Magistrados Brasileiros. Ano 5, n. 10, $1^{\circ}$ Semestre de 2001.

BRASIL. Lei $n^{\circ} 3071$, de $1^{\text {o }}$ de janeiro de 1916. Constituição Federal, Código Civil, Código de Processo Civil: acompanhados de legislação complementar. CAHALI, Yussef Said (Org.). 3. ed. rev., atual. e ampl. São Paulo: Revista dos Tribunais, 2001.

BRASIL. Lei $\mathrm{n}^{\mathbf{o}}$ 10406, de 10 de janeiro de 2002. Vade mecum. Obra coletiva de autoria da Editora Saraiva com a colaboração de PINTO, Antônio Luiz de Toledo; WINDT, Márcia Cristina Vaz dos Santos; CÉSPEDES, Lívia. 7. ed. atual. e ampl. São Paulo: Saraiva, 2009.

FERREIRA FILHO, Manoel Gonçalves. Direitos humanos fundamentais. São Paulo: Saraiva, 1995.

JUSTEM FILHO, Marçal. Desconsideração da personalidade jurídica no direito brasileiro. São Paulo: Revista dos Tribunais, 1979.

KOURY, Susy Elizabeth Cavalcante. A desconsideração da personalidade jurídica (diregard doctrine) e os grupos de empresas. Rio de Janeiro: Forense, 2000.

LAFER, Celso. A Reconstrução dos Direitos Humanos. São Paulo: Companhia das Letras, 1991.

MONTEIRO, Washington de Barros. Curso de Direito Civil. v. 1., 32. ed. São Paulo: Saraiva, 1996.

RODRIGUES, Silvio. Direito Civil. v. 1. São Paulo: Saraiva, 1985. 